\title{
Low Cost High Power Density Photovoltaic Power Conditioning System with an Energy Storage System
}

\author{
Du-Hee Jang ${ }^{*}$ and Sang-Kyoo Han ${ }^{\dagger}$ \\ $\dagger^{*}$ Dept. of Electronics Engineering, Kookmin University, Seoul, Korea
}

\begin{abstract}
A new low cost high power density photovoltaic power conditioning system (PV PCS) with an energy storage system is proposed in this paper. Its high power density and cost effectiveness can be achieved through the unification of the maximum power point tracker and the battery charger/discharger. Despite the reduced power stage, the proposed system can achieve the same performance in terms of maximum power point tracking and battery charging/discharging as the conventional system. When a utility power failure happens, the proposed system cannot perform maximum power point tracking at the UPS mode. However, the predetermined battery voltage near the maximum power point of the PV array can effectively generate a reasonable PV power even at the UPS mode. Therefore, it features a simpler structure, less mass, lower cost, and fewer devices. Finally, to confirm the operation, validity, and features of the proposed system, a theoretical analysis and experimental results from a single phase AC $220 \mathrm{Vrms} / 1.5 \mathrm{~kW}$ prototype are presented.
\end{abstract}

Key words: Energy storage system, Maximum power point tracking, Photovoltaic, Renewable energy

\section{INTRODUCTION}

Due to the information industry's constantly growing energy demand and the rapid depletion of fossil-fuel reserves, there is a great interest in alternative energy sources nowadays. In recent years, much effort has been made to find renewable clean energy sources in countries all over the world. Among them, solar energy with its silent operation, no installation area limitation, and no additional maintenance cost is well known as a suitable energy source for both residences and buildings. Since the 1970s, solar energy photovoltaic power has played an important role in alleviating the energy crisis, reducing environmental pollution, and reducing the greenhouse effect.

Recently, the application of photovoltaic assisted uninterruptible power supply (UPS) systems for poor quality utility power have been reported [1]-[4] where a photovoltaic system with energy storage elements composed of a maximum power point tracker (MPPT), a bi-directional converter (BDC) for the battery, and a DC/AC inverter is

Manuscript received Feb. 17, 2011; revised Mar. 26, 2012

Recommended for publication by Associate Editor Woo-Jin Choi.

${ }^{\dagger}$ Corresponding Author: djhan@kookmin.ac.kr

Tel: +82-2-910-5467, Fax: +82-2-910-4449, Kookmin University

*Dept. of Electronics Engineering, Kookmin University, Korea commonly used as shown in Fig.1 [5]-[9].

The MPPT employs the boost converter to perform the maximum power point tracking [10]-[16] and then it converts the wide range of photovoltaic (PV) array voltages $\left(150-420 \mathrm{~V}_{\mathrm{DC}}\right)$ into the maximum allowable line voltage. The BDC employs the bi-directional converter to charge and discharge the battery under normal operation and grid power failures, respectively. The DC/AC inverter injects the ac current in phase with the line voltage to the grid or it transfers the grid power to the link to charge the battery through power factor correction. Especially, when grid power failures happen, the battery is discharged and at the same time, the inverter generates an $\mathrm{AC}$ voltage source equal to the grid power to drive the load.

As mentioned above, a conventional PV system is effective for interfacing with the utility and for providing reliable power to the load even in the event of a power failure. However, since a conventional system consists of a MPPT, a $\mathrm{BDC}$, and an inverter, it has several serious drawbacks such as a high cost of production and a bulky system.

To solve these problems, a two-stage PV PCS has already been proposed [17]-[19]. It consists of a boost converter and a bi-directional inverter (BDI) and its link capacitors are replaced with a high voltage battery. Therefore, it features cost effectiveness and UPS function when there is a grid power failure. 


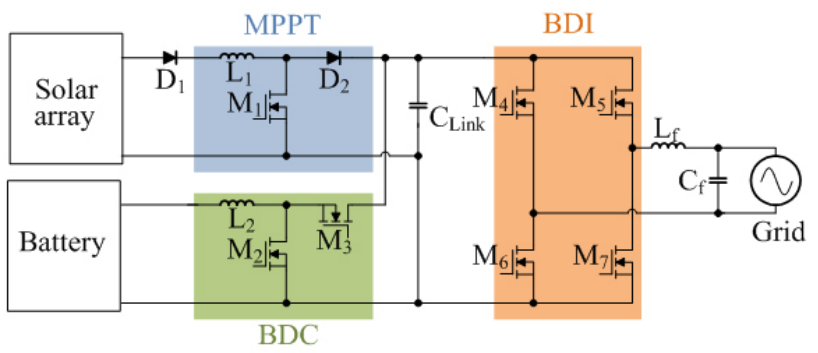

Fig. 1. Conventional photovoltaic system with energy storage system.

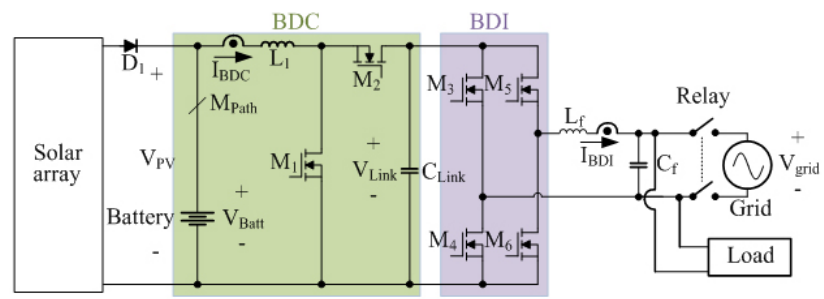

Fig. 2. Circuit configuration of the proposed PV PCS.

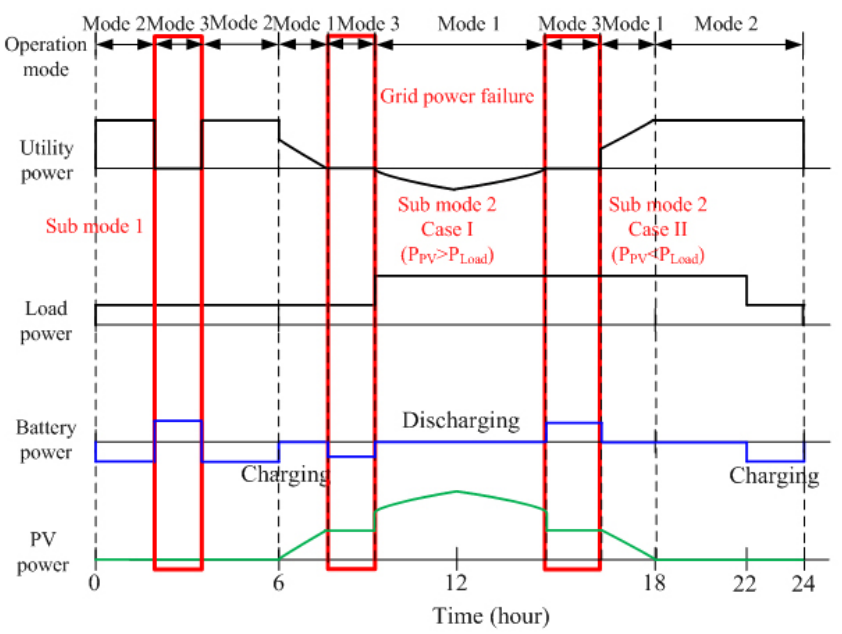

Fig. 3. Daily operations of proposed system.

However, since a large number of batteries have to be serially connected to produce the maximum allowable line voltage, the burden on the battery management system (BMS) is too severe to prevent the voltage unbalance of each battery cell.

To overcome all of these drawbacks, a new photovoltaic power conditioning system with an energy storage system is proposed in this paper. Unlike the conventional PV PCS, the proposed system integrates the MPPT and the BDC as one power stage, as shown in Fig 2. Therefore, it features high power density and cost effectiveness.

\section{ANALYSIS OF THE PROPOSED PV PCS}

Fig. 2 shows the circuit configuration of the proposed PV

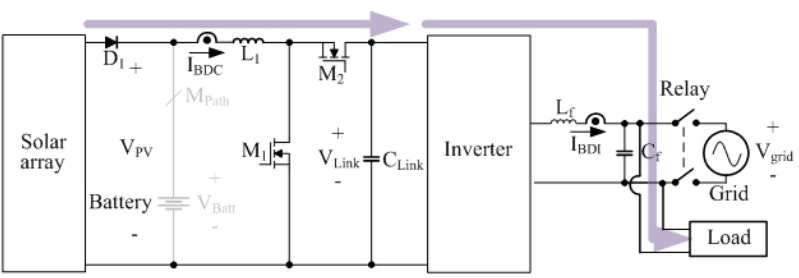

(a) PV generation mode.

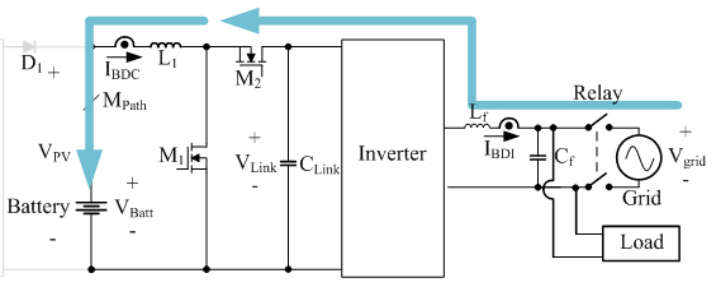

(b) Battery charge mode.

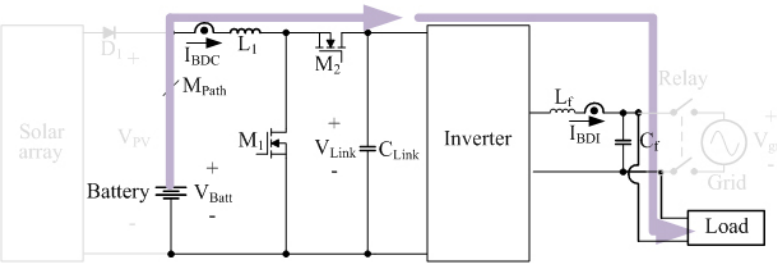

(c) Sub mode 1 at UPS mode.

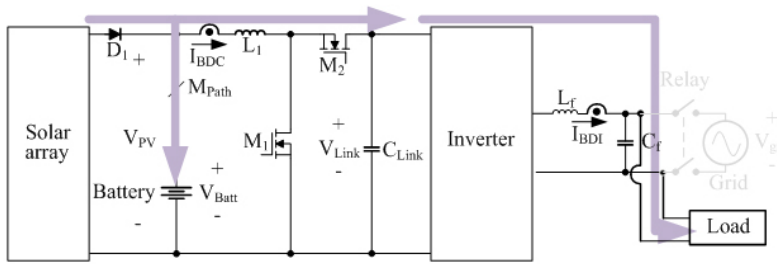

(d) Sub mode 2 at UPS mode (Case I: $\left.\mathrm{P}_{\mathrm{PV}}>\mathrm{P}_{\text {Load }}\right)$.

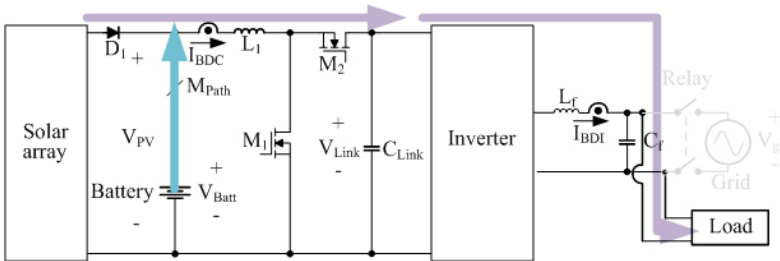

(e) Sub mode 2 at UPS mode (Case II: $\mathrm{P}_{\mathrm{PV}}<\mathrm{P}_{\text {Load }}$ ).

Fig. 4. Power flow of proposed system.

PCS with an energy storage system. The proposed system is composed of a BDI and a BDC integrating the MPPT and battery charger/discharger. Therefore, since the integrated BDC can perform the MPPT and battery charge/discharge with only one power stage, it features a lower cost and a smaller system size.

\section{A. Classification of the Proposed System Operations}

According to the possible power flow conditions between 


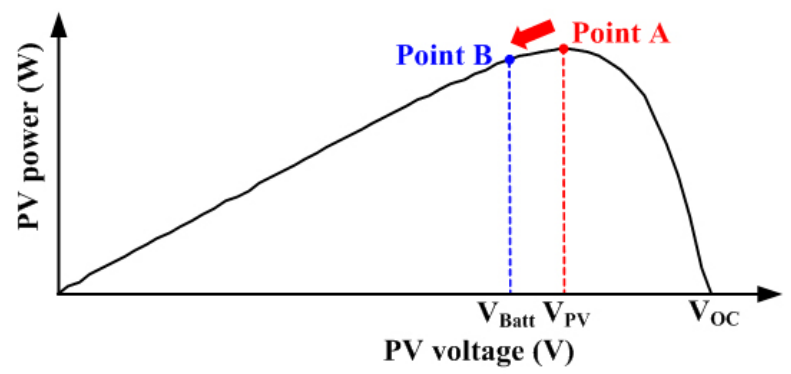

(a) $V_{P V}>V_{\text {Batt. }}$

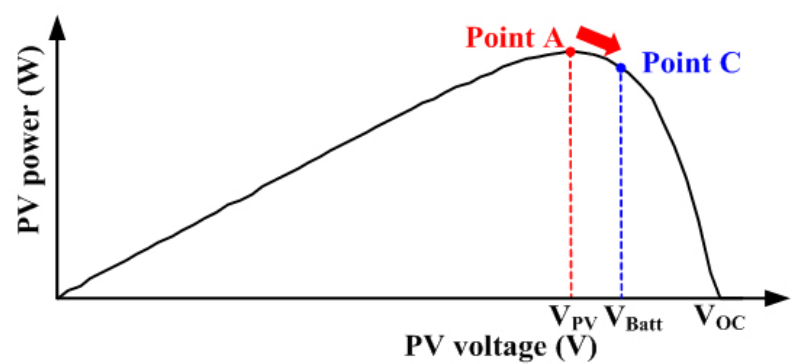

(b) $\mathrm{V}_{\mathrm{PV}}<\mathrm{V}_{\text {Batt. }}$

Fig. 5. P-V Curve according to the voltage of PV array.

the BDC and the BDI, the proposed system can be categorized into three possible operation modes: the PV generation mode during the insolation period, the UPS mode during utility power failures, and the battery charge mode during the night.

Fig. 3 shows the modified design example suggested in [17]. Since the PV power is absent from midnight to daybreak, the utility simultaneously charges the battery and supplies the load power with low cost midnight power. Additionally, when a utility power failure happens during that period, the battery supplies the load power and consequently, the UPS mode is performed.

During daylight, the power generated from the PV array is fed to the utility. When a utility power failure happens, the load power is supplied by both the battery and the PV array. The detailed operation modes of the proposed PV PCS according to the three possible operation modes are described as follows.

\section{B. Operation Modes of the Proposed PV PCS}

(a) Mode 1 (PV generation mode during the insolation period): During daylight, the path switch $\mathrm{M}_{\text {path }}$ is turned off and the power generated from the PV array is fed to the utility as shown in Fig. 4(a). The operation in this mode is same as that of a synchronous boost converter. The synchronous rectifier $\mathrm{M}_{2}$ is driven complementarily with the main switch $\mathrm{M}_{1}$.
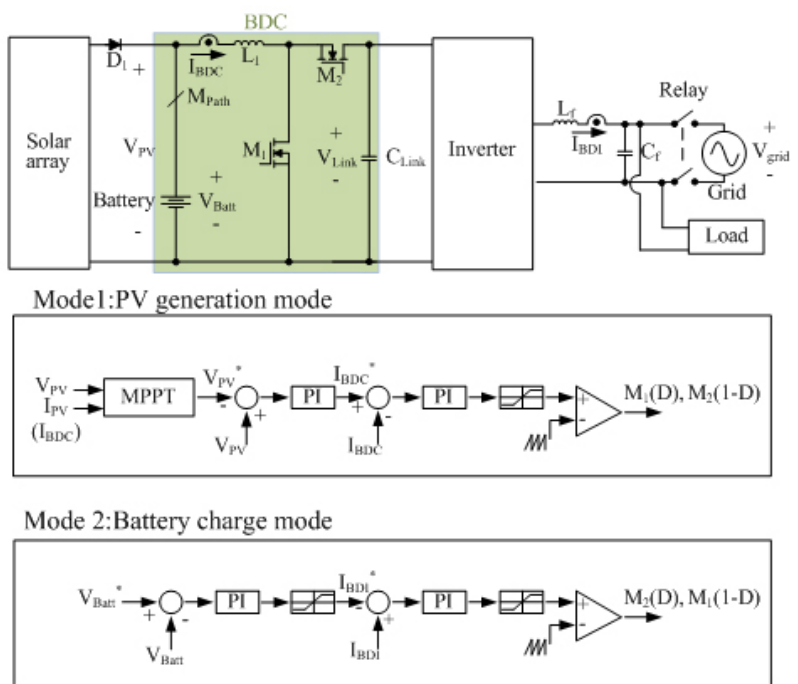

Mode 3:UPS mode

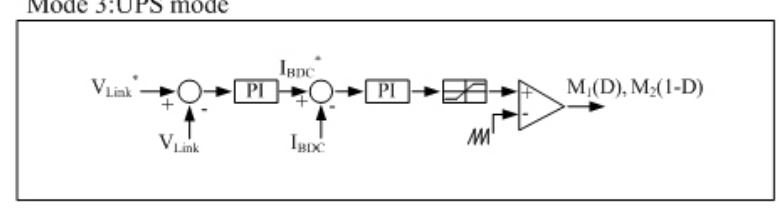

Fig. 6. Block diagram of proposed system.

(b) Mode 2 (battery charge mode during the night): The power flow of the proposed system for a power transfer from the utility to the battery is shown in Fig. 4(b). When the path switch $\mathrm{M}_{\text {path }}$ is turned on, the proposed converter charges the battery from the utility. Unlike the PV generation mode, the switch $\mathrm{M}_{2}$ acts as a main switch and $\mathrm{M}_{1}$, as a synchronous rectifier, is complementarily driven with $\mathrm{M}_{2}$.

(c) Mode 3 (UPS mode during utility power failures): When a utility power failure occurs, the path switch $\mathrm{M}_{\text {path }}$ is turned on and the UPS mode begins. As shown in Fig. 4(c), (d) and (e), the operation modes are divided into two sub-modes depending on the insolation. One is from sunset to daybreak and the other is during daylight. The operation of the former is similar to that of the battery charge mode except for the direction of the inductor current and the control target. The power flow of the proposed system for a power transfer from the battery to the load is shown in Fig. 4(c). On the other hand, the operation of the latter is somewhat different, which is due to the fact that the PV power can also be transferred to the load or the battery. Namely, unlike Mode 1 and Mode 2, the two sources of the PV array and the battery are connected in parallel. Therefore, the UPS mode during daylight can be divided into two cases according to the possible power flow conditions.

- CASE I $\left(\mathrm{P}_{\mathrm{PV}} \geq \mathrm{P}_{\text {Load }}\right)$ : When the PV power $\mathrm{P}_{\mathrm{PV}}$ is larger than the load power $\mathrm{P}_{\text {Load, }}$, the power corresponding to $\mathrm{P}_{\text {load }}$ of $\mathrm{P}_{\mathrm{PV}}$ is transferred to the load and the residual 


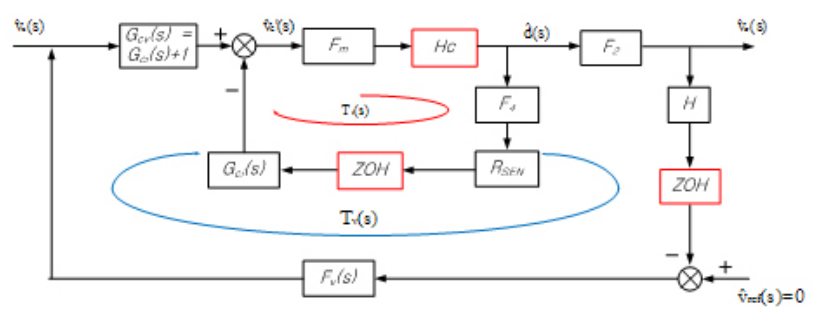

Fig. 7. Control block diagram for BDC part.

TABLE I

Transfer Function Of Proposed System

\begin{tabular}{c|c|c|c}
\hline Item & $\begin{array}{c}\text { PV } \\
\text { generation } \\
\text { mode }\end{array}$ & $\begin{array}{c}\text { Battery charge } \\
\text { mode }\end{array}$ & UPS mode \\
\hline \hline $\mathrm{V}_{\mathrm{O}}$ & $\mathrm{V}_{\mathrm{PV}}$ & $\mathrm{V}_{\text {Batt }}$ & $\mathrm{V}_{\text {Link }}$ \\
\hline $\mathrm{F}_{2}$ & $\frac{1}{D^{\prime 2} L_{e}} \frac{s+\frac{1}{C R_{L}}}{\Delta}$ & $\frac{1}{D^{\prime 2} L_{e}} \frac{s+\frac{1}{C R_{L}}}{\Delta}$ & $\frac{V_{g}}{D^{\prime 2} L_{e} C} \frac{\left[s C R_{c}+1\right]\left[1-s \frac{L_{e}}{R_{L}}\right]}{\Delta}$ \\
\hline $\mathrm{F}_{4}$ & $\frac{V_{g}}{D^{\prime 3} L_{e}} \frac{s+\frac{2}{C R_{L}}}{\Delta}$ & $\frac{V_{g}}{L} \frac{s+\frac{1}{C R_{L}}}{\Delta}$ & $\frac{V_{g}}{D^{\prime 3} L_{e}} \frac{s+\frac{2}{C R_{L}}}{\Delta}$ \\
\hline $\mathrm{L}_{\mathrm{e}}$ & $L_{e}=\frac{L}{D^{\prime 2}}$ & $\mathrm{~L}$ & $L_{e}=\frac{L}{D^{\prime 2}}$ \\
\hline $\mathrm{R}_{\mathrm{eq}}$ & $\frac{R_{l}}{D^{\prime 2}}$ & $R_{l}$ & $\frac{R_{l}}{D^{\prime 2}}$ \\
\hline $\mathrm{H}_{\mathrm{c}}$ & \multicolumn{2}{|c}{$\mathrm{HOH}\left(\frac{T s}{2}\right)=e^{-s \frac{T s}{2}}$} \\
\hline $\mathrm{ZOH}$ & \multicolumn{2}{|c}{$s$} \\
\hline
\end{tabular}

$$
\Delta=s^{2}+s\left[\frac{R_{e q}+R_{c}}{L_{e}}+\frac{1}{C R_{L}}\right]+\frac{1}{L_{e} C}
$$

power $\mathrm{P}_{\mathrm{PV}}-\mathrm{P}_{\text {Load }}$ is transferred to the battery, as shown in Fig. 4(c).

- CASE II $\left(\mathrm{P}_{\mathrm{PV}}<\mathrm{P}_{\text {Load }}\right)$ : When the $\mathrm{PV}$ power $\mathrm{P}_{\mathrm{PV}}$ is smaller than the load power $\mathrm{P}_{\mathrm{Load}}$, all of the $\mathrm{PV}$ power $\mathrm{P}_{\mathrm{PV}}$ is transferred to the load and the shortage of power $\mathrm{P}_{\text {Load }}-\mathrm{P}_{\mathrm{PV}}$ is made up by the battery, as shown in Fig. 4(d).

As mentioned above, when the UPS mode begins, the voltage $\mathrm{V}_{\mathrm{pv}}$ across the PV array is changed by the parallel connection between the battery and the PV array. When the $\mathrm{PV}$ array voltage $\mathrm{V}_{\mathrm{PV}}$ at the maximum power point is higher than the battery voltage $V_{B a t t}, V_{P V}$ is clamped to $V_{\text {Batt }}$ by $M_{\text {path }}$ conducting, as shown in Fig. 4. Therefore, the PV power point is moved from $\mathrm{A}$ to $\mathrm{B}$, and the power generated from the PV array is decreased, as shown in Fig. 5(a). Similarly, when the PV array voltage $\mathrm{V}_{\mathrm{PV}}$ at the maximum power point is lower than the battery voltage $V_{\text {Batt }}, V_{P V}$ is clamped to $V_{\text {Batt }}$.
Therefore, the PV power point is moved from A to C, and the power generated from the PV array is decreased, as shown in Fig. 5(b).

As mentioned above, the proposed system cannot operate the maximum power point tracking in the UPS mode. However, if the battery voltage $\mathrm{V}_{\text {Batt }}$ is set to an appropriate value near the maximum power point, the proposed system can effectively use the PV power even in the UPS mode.

\section{Control of the Proposed System}

A block diagram of the proposed system is shown in Fig. 6 . As shown in this figure, its controller is consists of two parts, namely, the BDC and BDI controllers. The BDC controller is categorized into a PV generation mode, a battery charge mode, and a UPS mode. Each controller uses a PI controller which is easy to design and has a good dynamic performance. As the BDI part is exactly same as that of a conventional PV PCS, its detailed operational principles are skipped here.

\section{1) PV generation mode}

The operation of this mode is exactly same as that of a conventional PV PCS due to the disconnection between the battery and the PV array. The BDC controller at the PV generation mode is made up of an inner current and outer voltage control loops in the form of a cascade structure, as shown in Fig. 6. The BDC part controls the voltage and current of the PV array through the MPPT algorithm, where the well-known $\mathrm{P} \& \mathrm{O}$ algorithm is adopted for maximum power point tracking and it determines the PV array voltage command $\mathrm{V}_{\mathrm{PV}}$ *. Therefore, if the sensed $\mathrm{PV}$ array voltage is higher than the voltage command $\mathrm{V}_{\mathrm{PV}}{ }^{*}$, the duty ratio is increased and subsequently, the output voltage of the BDC is increased. On the contrary, if the sensed PV array voltage is lower than the voltage command $\mathrm{V}_{\mathrm{PV}}{ }^{*}$, the duty ratio and the output voltage are decreased.

\section{2) Battery charge mode controller}

The construction of the BDC controller at the battery charge mode is similar to that of the PV generation mode except that the control target is not the PV voltage but the battery voltage and the current direction is reversed. To prolong the battery life, a constant current control following a constant voltage control is adopted, as shown in Fig. 6. As battery voltage is charged up to its nominal value, the outer loop is dominated by the voltage controller, where the current will decrease gradually.

\section{3) UPS mode}

When a grid power failure happens, the path switch $\mathrm{M}_{\text {path }}$ is turned on and the UPS mode begins. The BDC controller is made up of a cascade structure like the previous mode. In order to obtain good dynamic performance and good noise immunity, the average current-mode control (ACMC) scheme 
is employed, as shown in Fig. 6. The ACMC adjusts the duty cycle of the BDC according to the difference voltage between the voltage command $\mathrm{V}_{\text {Link }}{ }^{*}$ and the sensed link capacitor voltage $\mathrm{V}_{\text {Link}}$.

\section{Digital Controller Design}

The proposed system is controlled with a TMS320F 28335 DSP. To design the digital controller, a small signal model for the BDC is derived [20]. Fig. 7 shows a control block diagram of the proposed BDC including the zero order holds and the computation delay. Table I shows its transfer function at each mode [21] [22].

From Fig.7 and Table I, the current loop gain $T_{i}$ at each mode can be obtained as follows:

$$
T_{i}=G_{c i} * \mathrm{ZOH} * H_{c} * R_{\text {sen }} * F_{4}
$$

where $\mathrm{G}_{\mathrm{ci}}=$ the current compensator transfer function, $\mathrm{ZOH}=$ the zero order holds, $\mathrm{H}_{\mathrm{c}}=$ the computation delay, $\mathrm{R}_{\mathrm{sen}}=$ the sensing gain, and $\mathrm{F}_{4}=$ the transfer function of the control-to-inductor current.

From equation (1), the current compensator $\mathrm{G}_{\mathrm{ci}}$ can be designed. In the same manner, the outer voltage loop gain $T_{v}$ at each mode can be obtained as follows:

$$
T_{v}=\frac{G_{c v} * F_{m} * H_{c} * F_{2} * H * Z O H}{1+T_{i}}
$$

where $\mathrm{G}_{\mathrm{cv}}=$ the voltage compensator transfer function, $\mathrm{F}_{\mathrm{m}}=$ the modulator gain, $\mathrm{F}_{2}=$ the control-to-output transfer function, and $\mathrm{H}=$ the output voltage sensing gain.

Fig. 8 shows a Bode diagram of the BDC at each mode. As shown in this figure, the designed phase and the gain margins are sufficient for a BDC with a closed loop.

\section{EXPERIMENTAL RESULTS}

In order to confirm the validity of the proposed PV PCS, a $1.5 \mathrm{~kW}$ prototype is built and implemented with following specifications:

- DSP: TMS320F28335

- PV array: $1.5 \mathrm{~kW}\left(\mathrm{~V}_{\mathrm{OC}}=290 \mathrm{~V}, \mathrm{I}_{\mathrm{SC}}=7.2 \mathrm{~A}\right)$

- Load power: $\mathrm{P}_{\text {load }}=250 \mathrm{~W}$

- Batteries: PNB12340 12V/30A * 13EA

- Utility: single-phase $220 \mathrm{Vrms} / 60 \mathrm{~Hz}$

- $\mathrm{L}=600 \mathrm{uH}, \mathrm{C}_{\mathrm{Link}}=1.36 \mathrm{mF}$

- Power switches: $\mathrm{M}_{1}$ and $\mathrm{M}_{2}=\mathrm{FQA24N60}$ (600V/24A)

- Switching frequency: $\mathrm{f}_{\mathrm{sw}}=30 \mathrm{kHz}$

- MPPT algorithm: P\&O (Perturbation and observation)

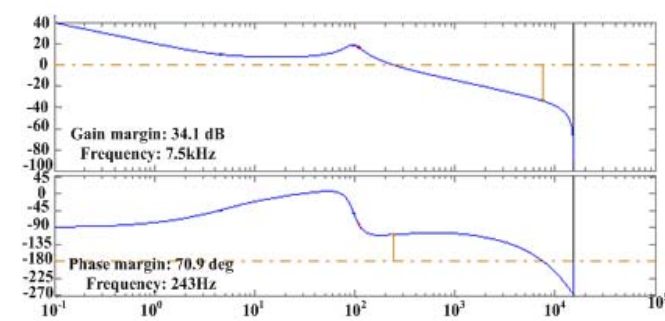

(a) Bode diagram of inner loop for PV generation mode.

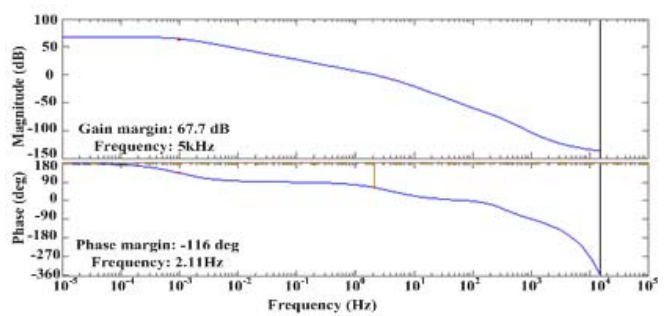

(b) Bode diagram of outer loop for PV generation mode.

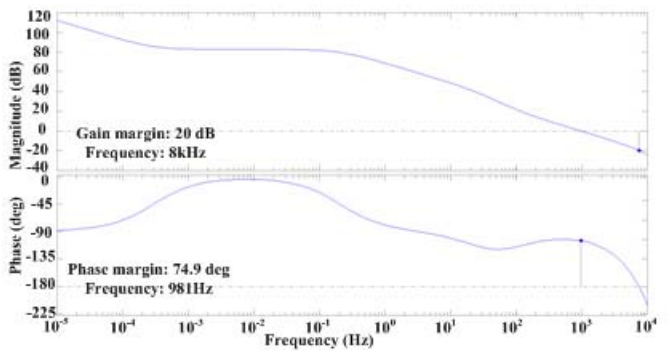

(c) Bode diagram of inner loop for battery charge mode.

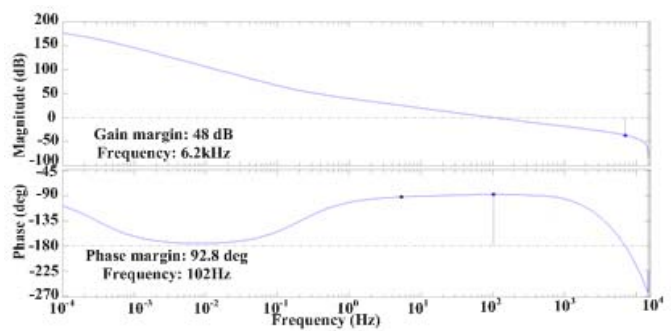

(d) Bode diagram of outer loop for battery charge mode.

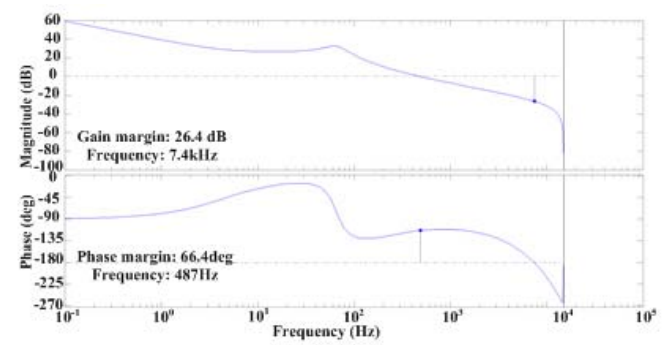

(e) Bode diagram of inner loop for UPS mode.

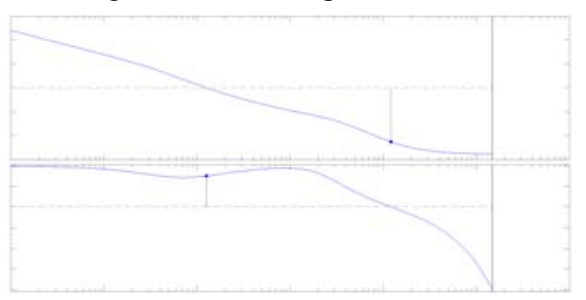

(f) Bode diagram of outer loop for UPS mode.

Fig. 8. Bode diagram of proposed system. 


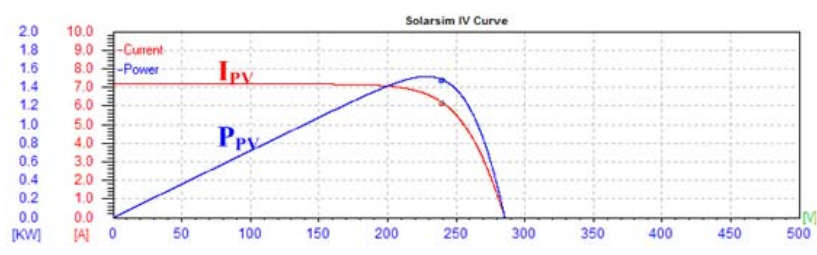

(a) P-V and V-I curve of the PV array.

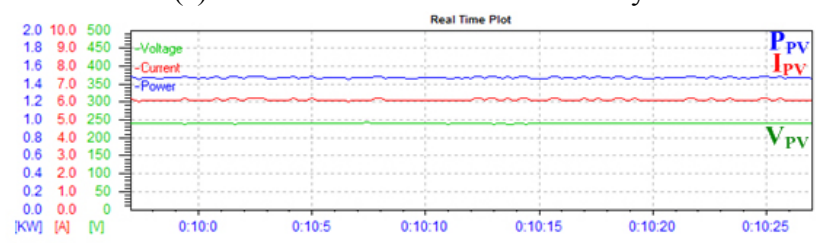

(b) The voltage, current, and power of PV array.

Fig. 9. Measured waveforms at the power transfer mode with $\mathrm{PV}$ power $\mathrm{P}_{\mathrm{PV}}=1.5 \mathrm{~kW}$.

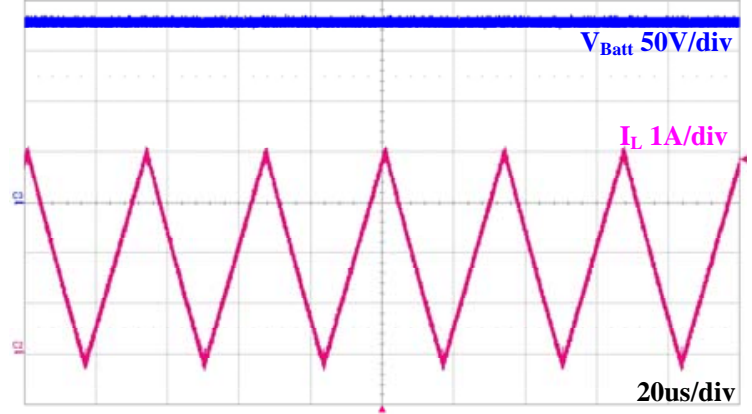

(a) Measured waveforms of BDC for the charge mode.

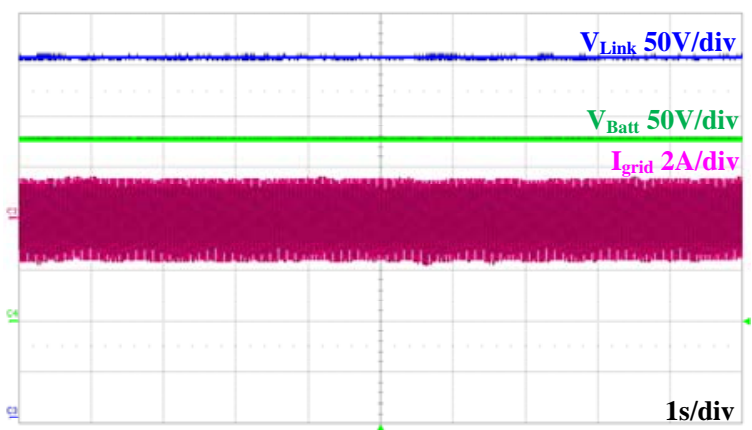

(b) Measured waveforms of BDC and inverter.

Fig. 10. Measured waveforms of the proposed system at charge mode.

\section{A. PV Generation Mode During The Insolation Period}

Fig. 9(a) shows the measured waveforms (the P-V and V-I curves of the PV array) at the PV generation mode during the insolation period. The maximum power point is about $1.483 \mathrm{~kW}$ with $\mathrm{V}_{\mathrm{MPP}}=239.3 \mathrm{~V}$. In addition, Fig. 9 (b) shows that the proposed converter can successfully perform the $\mathrm{P} \& \mathrm{O}$ algorithm and that it can accurately track the maximum power point.

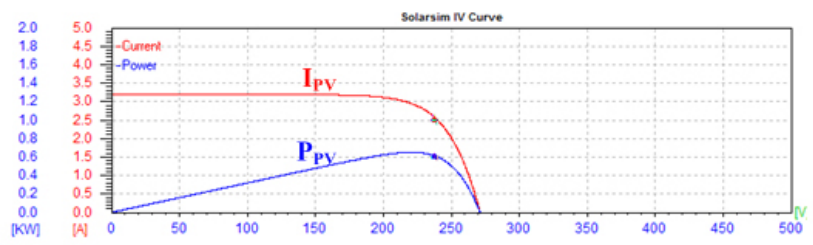

(a) Power and current curves at PV generation mode.

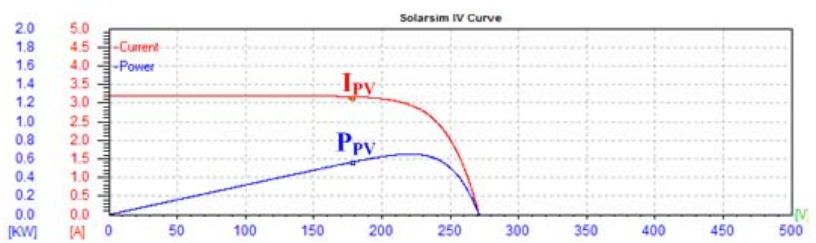

(b) Power and current curves at utility power failure.

Fig. 11. Operating point of PV array before and after the mode change.

\section{B. Battery Charge Mode During The Night}

Fig. 10 (a) shows the measured waveforms of the BDC at the battery charge mode during the night under a $220 \mathrm{~V}_{\mathrm{rms}}$ utility voltage. In addition, the voltage across the battery is charged with 1.06Arms and it is well regulated to be a constant $180 \mathrm{~V}$ by the BDC. Fig. 10 (b) shows the measured waveforms of the BDC and the inverter. The voltage across the link-capacitor is controlled to be a constant $350 \mathrm{~V}$ by the inverter.

\section{UPS mode during a utility power failure}

Fig. 11 shows the operating point of the PV array before and after the mode change from the PV generation mode to the UPS mode. Fig. 11(a) shows the power and current curves at the PV generation mode. The maximum power point is at about $650 \mathrm{~W}$ at $240 \mathrm{~V}$. Fig. 11 (b) shows the power and current curves at a utility power failure. Since the operating point of the PV array is changed from $240 \mathrm{~V}$ to $180 \mathrm{~V}$ due to the parallel connection of the PV array and battery, the PV power is reduced from $650 \mathrm{~W}$ to $558 \mathrm{~W}$.

Fig. 12(a) shows the measured waveforms at the UPS mode. When a utility power failure occurs, the operation of the proposed PV PCS is changed from the power transfer mode to the UPS mode and the switch $\mathrm{M}_{\text {path }}$ is turned on. Therefore, the voltage across the PV array is clamped to the battery voltage $180 \mathrm{~V}$. Fig. 12(b) shows the measured waveforms at the UPS mode at the steady state. The power corresponding to $\mathrm{P}_{\text {load }}=250 \mathrm{~W}$ of $\mathrm{P}_{\mathrm{PV}}=558 \mathrm{~W}$ is transferred to the load and the residual power $\mathrm{P}_{\mathrm{PV}}-\mathrm{P}_{\mathrm{Load}}=308 \mathrm{~W}$ is transferred to the battery.

Table II shows the comparative results between the conventional and proposed PV PCS in terms of the number of devices. The proposed system can be implemented with a smaller number of components. Therefore, it features a high power density and cost effectiveness. 


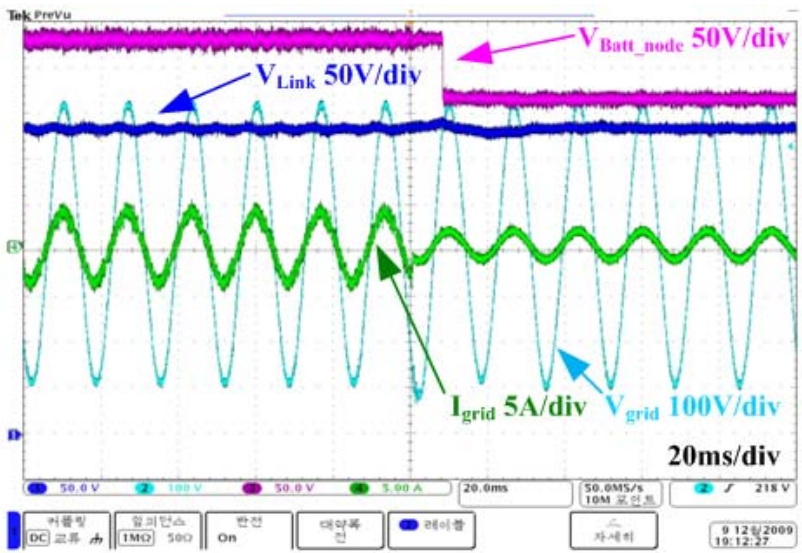

(a) Measured waveforms of the mode change.

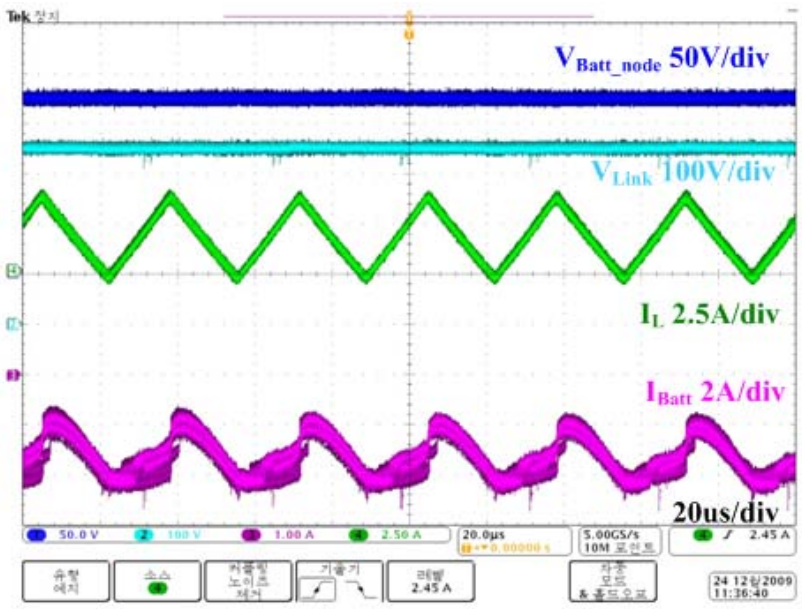

(b) Measured waveforms of BDC part.

Fig. 12. Measured waveforms at UPS mode with PV power $\mathrm{P}_{\mathrm{MPPT}}=650 \mathrm{~W}$.

TABLE II

Comparative Results Between Conventional and Proposed SYSTEM

\begin{tabular}{|c|c|c|c|}
\hline \multicolumn{2}{|c|}{ Items } & $\begin{array}{c}\text { Conventional } \\
\text { system }\end{array}$ & Proposed system \\
\hline \multirow{5}{*}{$\begin{array}{c}\text { Power } \\
\text { stage }\end{array}$} & Inductor & 2EA & $1 \mathrm{EA}$ \\
\hline & $\begin{array}{l}\text { Current } \\
\text { sensor }\end{array}$ & 2EA & 1EA \\
\hline & Switch & 3EA & 2EA \\
\hline & Gate driver & $3 \mathrm{EA}$ & $2 \mathrm{EA}$ \\
\hline & Diode & 2EA & 1EA \\
\hline
\end{tabular}

\section{CONCLUSIONS}

Since a conventional system consists of three power stages (MPPT, BDC, and inverter), it has several drawbacks such as a bulky system and a high cost of production. To overcome these drawbacks, a new low cost high power density photovoltaic power conditioning system with an energy storage system is proposed in this paper. The higher power density and lower cost PVPCS can be achieved by merging the maximum power point tracker and the battery charger/discharger into one power stage. Nevertheless, it can achieve similar performances to the conventional system during the following periods: PV generation, battery charge, and utility power failures after sunset. This is possible because the MPPT and the battery charger/discharger do not operate simultaneously during above-mentioned periods. Since both the photovoltaic and battery energies can be supplied to the load during a utility power failure period during daylight, the efficient handling of photovoltaic energy can be obtained. Finally, experimental results obtained on a $1.5 \mathrm{~kW}$ prototype show the high performance of the proposed system.

Therefore, the proposed system is expected to be well suited to use as a high power density and cost effective PV PCS due to its simpler structure, reduced mass, lower cost, and fewer devices, simpler structure, less mass, lower cost, and fewer devices.

\section{ACKNOWLEDGMENT}

This work was supported (in part) by the Research Program 2012 of Kookmin University, Korea and the MKE (The Ministry of Knowledge Economy), Korea, under the ITRC (Information Technology Research Center) support program supervised by the NIPA (National IT Industry Promotion Agency) (NIPA-2012-H0301-12-2007)

\section{REFERENCES}

[1] C. J. Hatziadoniu, F. E. Chalkiadakis, and V. K . Feiste, “A power conditioner for a grid-connected photovoltaic generator based on the 3-level inverter," IEEE Trans. Energy Convers., Vol. 14, No. 4, pp. 1605-1610, Dec. 1999.

[2] M. Ashari. W. W. L. Keerthipala, and C. V. Nayar, "A single phase parallely connected uninterruptible power supply demand side management system," IEEE Trans. Energy Convers., Vol. 15, No. 1, pp. 97-102, Mar. 2000.

[3] H. Him and P. Mutschler, "Voltage source inverter for grid connected photovoltaic systems," 2nd World Conference and Exhibition on Photovoltaic Solar Energy Conversion, Vienna, Australia, pp. 2045-2048, Jul. 1998.

[4] I.-B. Song; D.-Y. Jung, Y.-H. Ji, S.-C. Choi, S.-W. Lee, and C.-Y. Won, "A residential 10kWh lithium-polymer battery energy storage system," Power Electronics and ECCE Asia 2011 conference, pp. 2625-2630, 2011.

[5] J. Xue, Z.Yin, B. Wu, Z. Wu, and J. Li, "Technology research of novel energy storage control for the pv generation system," Power and Energy Engineering Conference, pp. 1-4, 2009. 
[6] P. Bolduc, D. Lehmicke, and J. Smith, "Performance Of A Grid-Connected Pv System With Energy Storage," Photovoltaic Specialists Conference, pp. 1159-1162, 1993.

[7] S. X. hen and H. B. Gooi,"Scheduling of energy storage in a grid-connected PV/battery system via SIMPLORER," TENCON 2009 - 2009 IEEE Region 10 Conference, pp.1-5, 2009.

[8] Y. Riffonneau, S. Bacha, F. Barruel, and A. Delaille, "Energy flow management in grid connected PV systems with storage - A deterministic approach," ICIT 2009, IEEE International Conference, pp. 1-6, 2009.

[9] Y. Riffonneau., S. Bacha, F. Barruel, S. Ploix, "Optimal power flow management for grid connected pv systems with batteries," IEEE Trans. Sustainable Energy, Vol. 2, pp. 309-320, Jun. 2011.

[10] D. P. Hohm and M. E. Ropp, "Comparative study of maximum power point tracking algorithms using an experimental, programmable, maximum power point tracking test bed," Photovoltaic specialists conference, pp. 1699-1702, 2000.

[11] M. Veerachary, T. Senjyu, and K. Uezato, "Voltage-based maximum power point tracking control of PV system," IEEE Trans. Aerosp. Electron. Syst., Vol. 38, No. 1, pp. 262-270, Jan. 2002.

[12] K. K. Tse, M. T. Ho, H. S.-H. Chung, and S. Y. Hui, "A novel maximum power point tracker for PV panels using switching frequency modulation," IEEE Trans. Power Electron., Vol. 17, No. 6, pp. 980-989, Nov. 2002.

[13] P. Midya, P. Krein, R. Turnbull, R. Reppa, and J. Kimball, "Dynamic maximum power point tracker for photovoltaic applications," in Proc. 27th Annu. IEEE Power Electronics Specialists Conf., pp. 1710-1716, 1996.

[14] E. Koutroulis, K. Kalaitzakis, and N. C. Voulgaris, "Development of a microcontroller-based, photovoltaic maximum power point tracking control system," IEEE Trans. Power Electron., Vol. 16, No. 1, pp. 46-54, Jan. 2001.

[15] T. Noguchi, S. Togashi, and R. Nakamoto, "Short-current pulse-based maximum-power-point tracking method for multiple photovoltaic-andconverter module system," IEEE Trans. Ind. Electron., Vol. 49, No. 1, pp. 217-223, Feb. 2002.

[16] C. Hua, J. Lin, and C. Shen, "Implementation of a DSP-controlled photovoltaic system with peak power tracking," IEEE Trans. Ind. Electron., Vol. 45, No. 1, pp. 99-107, Feb. 1998.

[17] S. J. Chiang, K. T. Chang, and C. Y. Yen, "Residential photovoltaic energy storage system," IEEE Trans. Ind. Electron., Vol. 45, No. 3, pp. 385-394, Jun. 1998.

[18] J.-F. Chen, L.-Y. Chiang, C.-L. Chu, Y.-L. Lee, and T.-J. Liang, "Study and implementation of the single-phase three-wire photovoltaic energy conversion system," Proceedings of the IEEE 1999 International Conference, pp. 692-695, 1999.
[19] Y.-K. Lo, T.-P. Lee, and K.-H. Wu, "Grid-connected photovoltaic systems with power factor correction," IEEE Trans. Ind. Electron., Nol. 55, No. 5, pp. 2224-2227, May 2008.

[20] A. Prodic, D. Maksimovic, R. W. Erickson, "Design and implementation of a digital PWM controller for a high-frequency switching DC-DC power converter," Industrial Electronics Society, IECON 2001, Vol. 2, pp. 893-898, 2001.

[21] W. Tang, F. C. Lee, and R. B. Ridley, "Small-signal modeling of average current-mode control," IEEE Trans. Power Electron., Vol. 8, pp. 112-119, Mar. 1993.

[22] V. Vorpérian, "Simplified analysis of pwm converters using model of pwm switch. part1:continuous conduction mode," IEEE Trans. Aerosp. Electron. Syst., Vol. 26, No. 3, pp. 490-496, May 1990.

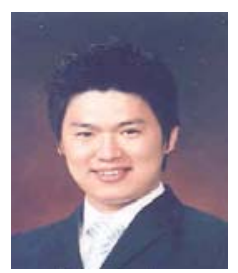

Du-Hee Jang received his B.S. and M.S. in Electronic Engineering from Kookmin University, Seoul, Korea, in 2007, and 2009, respectively, where he is currently working toward his Ph.D. His current research interests include the analysis, modeling, design, and control of power converters.

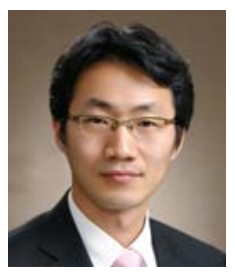

Sang-Kyoo Han received his B.E. in Electrical Engineering from Pusan National University, Pusan, Korea, in 1999, and his M.S. and Ph.D. in Electrical Engineering and Computer Science from the Korea Advanced Institute of Science and Technology (KAIST), Daejeon, Korea, in 2001 and 2005, respectively. For the next six months, he was a Post-Doctoral Fellow at KAIST where he developed digital display power circuits in addition to performing several other research activities. Since 2005, he has been with the Department of Electrical Engineering, Kookmin University, Seoul, Korea, as an Assistant Professor. He has also worked for the Samsung Power Electronics Center (SPEC) and the Samsung Network Power Center (SNPC) as a Research Fellow. His current research interests include power converter topologies, PFC converters, LED drivers, renewable energy systems, and battery chargers for electric vehicles. Dr. Han is a member of the Korean Institute of Power Electronics (KIPE). 